\title{
Optymalizacja terapii niewydolności serca w Polsce - opinia prezesów Sekcji Farmakoterapii Sercowo-Naczyniowej Polskiego Towarzystwa Kardiologicznego
}

\author{
Krzysztof J. Filipiak, Filip M. Szymański, Marcin Barylski, \\ Artur Mamcarz, Beata Wożakowska-Kapłon
}

Wytyczne leczenia przewlekłej niewydolności serca (NS) opublikowane przez Europejskie Towarzystwo Kardiologiczne (ESC, European Society of Cardiology) w 2016 roku są, wydawałoby się, dokumentem już powszechnie znanym i od czasu przetłumaczenia i ekspresowego opublikowania na łamach „Kardiologii Polskiej” szeroko dostępnym. Dla upowszechnienia ich stosowania w Polsce najwięcej zrobiła niewątpliwie Sekcja Niewydolności Serca Polskiego Towarzystwa Kardiologicznego (PTK), a zwłaszcza kierujące nią Panie Profesor: Jadwiga Nessler i Ewa Straburzyńska-Migaj. To dzięki działaniom tej Sekcji wytyczne ESC są rozpoznawane i coraz powszechniej stosowane nie tylko w środowisku lekarzy kardiologów, ale - co ważniejsze internistów i lekarzy rodzinnych.

Mimo to nadal istnieje potrzeba optymalizacji leczenia farmakologicznego. Praktyka - w zakresie częstości stosowania leków poprawiających rokowanie w NS, a przede wszystkim w zakresie zwiększania ich dawek do tych maksymalnie tolerowanych - pozostawia bowiem wiele do życzenia. Rejestry przeprowadzane w Polsce, Europie, na świecie oraz pojedyncze prace epidemiologiczno-obserwacyjne potwierdzają, że mniejszym problemem jest stosowanie takich leków jak inhibitory konwertazy angiotensyny (inhibitory ACE), beta-adrenolityki, antagoniści aldosteronu niż leków nowszych, takich jak iwabradyna. Rejestr QUALIFY (Quality of adherence to guideline recommendations for live-saving treatment in heart failure: an international survey), oceniający częstość stosowania tych czterech leków na świecie w grupie pacjentów z NS, odnotował ich zastosowanie odpowiednio u $87 \%, 87 \%, 69 \%$, 33\%, podczas gdy w Polsce wymienione grupy leków przyjmowało odpowiednio 92\%, 97\%, 73\% i 14\% chorych. W analizowanych czterech grupach farmakoterapii iwabradyna wygląda też najgorzej, jeżeli chodzi o odsetek pacjentów, którzy otrzymują 100\% optymalnej dawki rekomendowanej. W rejestrze QUALIFY odsetki te dla inhibitorów ACE, beta-adrenolityków, antagonistów aldosteronu i iwabradyny wynosiły w Polsce odpowiednio $27 \%, 18 \%, 66 \%$ i $14 \%$. Wszystko to pozwala nam stwierdzić, że w Polsce wśród pacjentów z NS nadal za rzadko - pomimo historycznej decyzji o refundowaniu tego leku - stosowana jest iwabradyna. Pośrednio z tych liczb można wywnioskować, że nie najlepiej wygląda również kwestia optymalizacji częstości akcji serca u chorych z NS.

Jak to stwierdzenie i powyższe fakty zestawić z obowiązującymi wytycznym ESC dotyczącymi farmakoterapii szerokiej grupy pacjentów ze skurczową NS i obniżoną frakcją wyrzucania lewej komory? Wydaje się, że polscy lekarze dość dobrze adaptują do swojej praktyki krok pierwszy nowego algorytmu ESC, a więc leczenie za pomocą inhibitora ACE i beta-adrenolityku. Zaskakująco dobrze wdrażany jest też krok drugi, a więc stosowanie antagonisty aldosteronu, co cieszy nas jeszcze bardziej - częstsze stosowanie nowoczesnego eplerenonu, a nie starszego, obdarzonego gorszym profilem tolerancji spironolaktonu. Wydaje się natomiast, że działania edukacyjne powinny dotyczyć kroku trzeciego, zwłaszcza że wytyczne ESC wprowadziły w nim pewne utrudnienie, proponując de facto trzy możliwości realizacji, a więc: zastosowanie nowej grupy leków (ARNI - antagoniści receptory dla angiotensyny połączone z inhibitorem neutralnej endopeptydazy, w praktyce jeden lek: połączenie walsartanu z sakubitrilem), rozważenie wskazań do resynchronizacji lub zastosowanie iwabradyny (ryc. 1).

Lekarz teoretycznie może skorzystać z jednego, dwóch lub trzech elementów trzeciego kroku, indywidualnie dobierając działania na podstawie szczegółowych wskazań, przeciwwskazań, wad i zalet danego postępowania. Te ostatnie elementy nie są, naszym zdaniem, dostatecznie przedyskutowane w wytycznych ESC, chociaż nas to nie dziwi - wytyczne mają charakter ogólny, nie odnoszą się do poszczególnych krajów, nie biorą pod uwagę specyfiki leczenia w danym państwie: sytuacji organizacji ochrony zdrowia, warunków refundacji określonych leków czy technologii medycznych. 


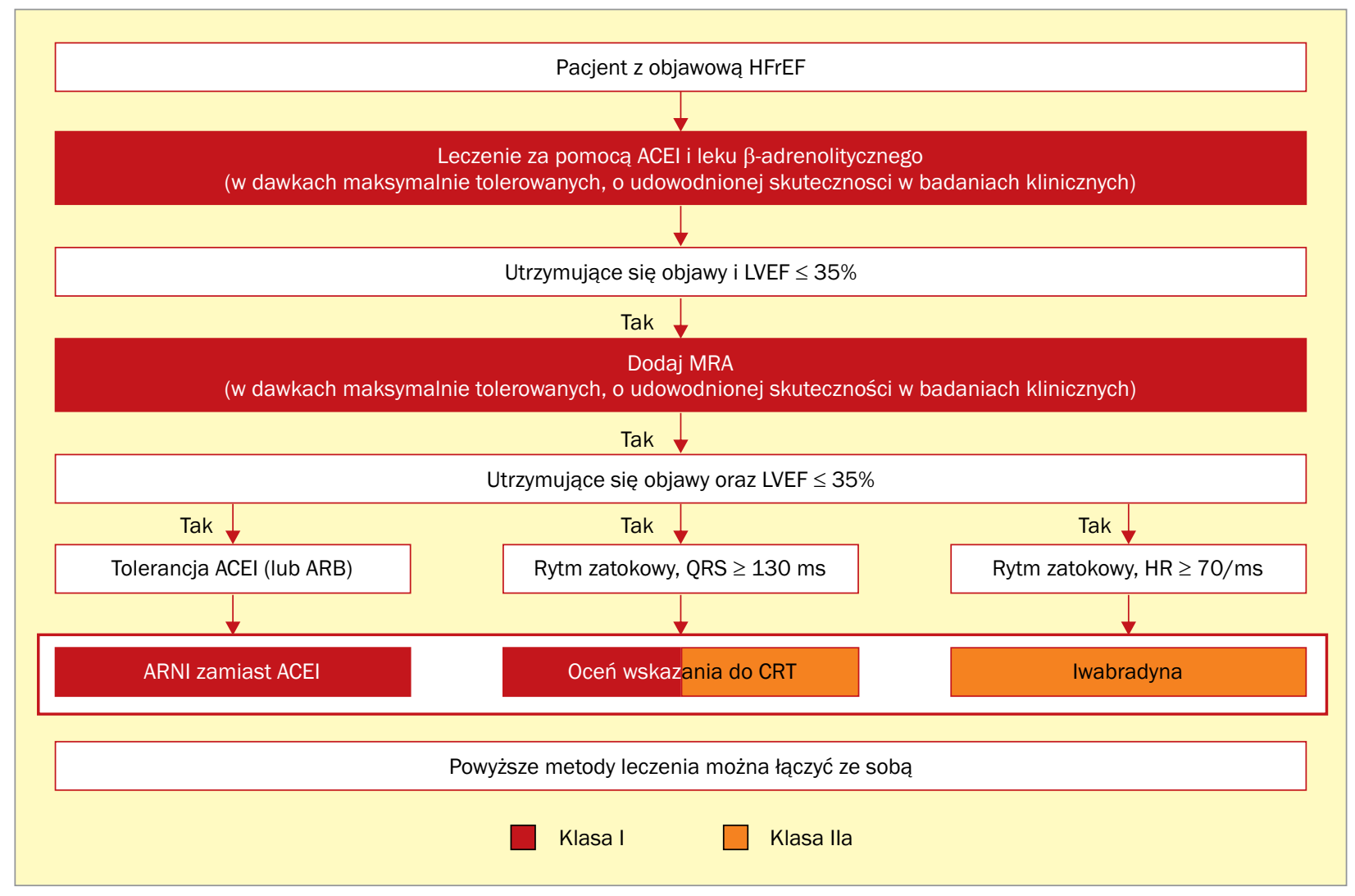

Rycina 1. Fragment algorytmu trzech kroków terapii pacjentów z niewydolnością serca ze zredukowaną frakcją wyrzucania lewej komory (HFrEF) z 2016 roku. ACEI - inhibitory konwertazy angiotensyny; LVEF - frakcja wyrzucania lewej komory serca; MRA - antagonista aldosteronu; ARB - sartan; QRS - szerokość odstępu QRS w zapisie elektrokardiograficznym; HR - częstość akcji serca; ARNI - połączenie sartanu z inhibitorem neutralnej endopeptydazy; CRT - elektryczna terapia resynchronizująca; przedrukowano za zgodą z: Ponikowski P, Voors AA, Anker SD et al. Wytyczne ESC dotyczące diagnostyki i leczenia ostrej i przewlekłej niewydolności serca w 2016 roku. Kardiol Pol. 2016; 74(10): 1037-1147, doi: 10.5603/KP.2016.0141 (rycina została zmodyfikowana)

Stąd pozwoliliśmy sobie na krótkie podsumowanie wad i zalet składowych trzeciego kroku z punktu widzenia lekarza praktyka, jak też sformułowanie najprostszych zaleceń dotyczących „optymalnego kandydata” do zastosowania danej składowej („U kogo rozważać w pierwszym rzędzie?”) oraz zaleceń do unikania tej składowej („U kogo raczej nie rozważać?”). Podsumowanie naszych dyskusji przedstawiliśmy w tabeli 1.

Powyższy zestaw zalet, wad, praktycznych wskazówek co do stosowania nieprzypadkowo pokrywa się z rzeczywistym obrazem leczenia pacjentów według kryterium trzeciego kroku w Polsce. Biorąc pod uwagę te trzy składowe trzeciego kroku oraz możliwości ich łączenia, największy odsetek chorych w Polsce leczonych jest iwabradyną, potem - metodami CRT. Trzecia co do częstości grupa to osoby stosujące równocześnie CRT i iwabradynę. Leczenie ARNI ograniczone jest aktualnie w Polsce jedynie do kilkudziesięciu chorych i ma marginalne znaczenie. Wszystkie te fakty skłoniły nas do opracowania wzoru listu do lekarza opiekującego się pacjentem z NS, który można wykorzystać w praktyce, analogicznie do listu, który opublikowaliśmy na łamach „Folia Cardiologica” w 2016 roku (Wożakowska-Kapłon B et al. Folia Cardiol. 2016; 11(4): 310-317), a który dotyczył opieki nad pacjentem po ostrym zespole wieńcowym.

Piśmiennictwo u Autorów. 
Tabela 1. Wady, zalety, optymalni kandydaci oraz sytuacje, w których nie myślimy o zastosowaniu poszczególnych składników trzeciego kroku z zaleceń leczenia NS z 2016 roku - zbiorcze opracowanie autorów listu dotyczące ARNI (walsartan/sakubitril), CRT (elektryczne metody terapii resynchronizującej) i iwabradyny

\begin{tabular}{|c|c|c|c|}
\hline & ARNI & CRT & IWABRADYNA \\
\hline Wady & $\begin{array}{l}\text { - wysokie koszty terapii } \\
\text { evidence-based medicine } \\
\text { (EBM) dotyczące tylko } \\
\text { porównania ARNI z enala- } \\
\text { prilem } \\
\text { - małe doświadczenie pol- } \\
\text { skich lekarzy } \\
\text { - } \quad \text { postrzeganie leku przez } \\
\text { pryzmat zmodyfikowanego } \\
\text { sartanu } \\
\text { - } \text { skomplikowany schemat } \\
\text { terapeutyczny dawkowania }\end{array}$ & $\begin{array}{l}\text { - } \quad \text { inwazyjnosć procedury } \\
\text { - } \text { mała dostępność dla pol- } \\
\text { skich pacjentów, antycypo- } \\
\text { wane problemy z finansowa- } \\
\text { niem inwazyjnych zabiegów } \\
\text { w przyszłości } \\
\text { - } \quad \text { konieczność posiadania } \\
\text { wykwalifikowanego zespołu } \\
\text { implantującego } \\
\text { - } \quad \text { konieczność wcześniejszej } \\
\text { optymalizacji terapii } \\
\text { - } \quad \text { problemy z kwalifikacją pa- } \\
\text { cjentów } \\
\text { - czéść pacjentów nie odpo- } \\
\text { wiada na terapię } \\
\text { - konieczność monitorowania } \\
\text { w ośrodku specjalistycznym }\end{array}$ & $\begin{array}{l}\text { - } \quad \text { konieczność obecności rytmu zatoko- } \\
\text { - } \quad \text { konieczność obecności podwyższonego } \\
\text { tętna } \\
\text { - } \quad \text { konfuzja co do tętna wskazującego po- } \\
\text { trzebę zastosowania (kryteria EBM czy } \\
\text { refundacji?) } \\
\text { - konieczność dokumentowania kryterium } \\
\text { - } \quad \text { wciąż zbyt małe doświadczenie ze sto- } \\
\text { sowaniem leku w Polsce }\end{array}$ \\
\hline Zalety & $\begin{array}{l}\text { - wysoki poziom rekomen- } \\
\text { dacji w aktualnych wytycz- } \\
\text { nych } \\
\text { - wykorzystanie nowych } \\
\text { mechanizmów patofizjolo- } \\
\text { gicznych w terapii }\end{array}$ & $\begin{array}{l}\text { - wysoki poziom rekomendacji } \\
\text { w wytycznych u określonych } \\
\text { grup pacjentów } \\
\text { - możliwość dalszego rozsze- } \\
\text { rzania metod elektroterapii } \\
\text { i telemonitoringu } \\
\text { - duża liczba badań klinicz- } \\
\text { nych }\end{array}$ & $\begin{array}{l}\text { - } \quad \text { wysoki poziom rekomendacji w wytycz- } \\
\text { - } \quad \text { wykorzystanie nowych mechanizmów } \\
\text { - } \quad \text { dużafizjologiczba badań klinicznych } \\
\text { - } \quad \text { wysoki profil bezpieczeństwa } \\
\text { - } \quad \text { łatwość włączania, stosowania i monito- } \\
\text { - } \quad \text { niskie koszia terapii } \\
\text { - } \quad \text { prosty schemat dawkowania } \\
\text { - } \quad \text { możliwość zastosowania w przypadku } \\
\text { - nietolerancji beta-adrenolityku } \\
\text { - możliwość wczesnego włączania razem } \\
\text { z beta-adrenolitykiem przy optymalizacji } \\
\text { - terapii } \\
\text { dowód na przedłużanie życia w podgru- } \\
\text { pie z HR > 75/min }\end{array}$ \\
\hline $\begin{array}{l}\text { U kogo w pierw- } \\
\text { szym rzędzie } \\
\text { rozważać? }\end{array}$ & $\begin{array}{l}\text { u chorych przewlekle le- } \\
\text { czonych dotąd enalaprilem } \\
\text { - w przypadku nieskutecz- } \\
\text { ności leczenia I i II krokiem } \\
\text { zgodnie z algorytmem }\end{array}$ & $\begin{array}{ll}\text { - } & \text { zmiany QRS o morfologii } \\
& \text { LBBB } \geq 130 \text { ms } \\
\text { - } & \text { zmiany QRS o morfologii nie- } \\
& \text {-LBBB } \geq 150 \mathrm{~ms}\end{array}$ & $\begin{array}{l}\text { - } \text { rytm zatokowy o częstości HR > 70/min } \\
\text { - } \text { brak możliwości stosowania lub zwięk- } \\
\text { szania dawki beta-adrenolityku } \\
\text { - istotna hipotonia uniemożliwiająca opty- } \\
\text { malizację leczenia }\end{array}$ \\
\hline $\begin{array}{l}\text { U kogo raczej } \\
\text { nie rozważać? }\end{array}$ & $\begin{array}{l}\text { - brak możliwości ekono- } \\
\text { micznych pacjenta } \\
\text { - } \quad \text { wywiad obrzęku Quinckego }\end{array}$ & 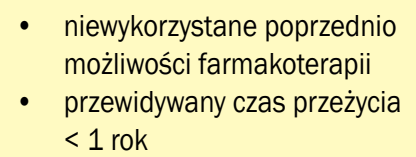 & $\begin{array}{ll}\text { - } & \mathrm{HR}<50 / \mathrm{min} \\
\text { - } & \text { ostra niewydolność serca }\end{array}$ \\
\hline
\end{tabular}


Sz. P.

Lekarz rodzinny / Lekarz specjalista przejmujący opiekę nad pacjentem

Szanowna Pani Doktor, Szanowny Panie Doktorze,

przejmują Państwo opiekę nad pacjentem z przewlekłą niewydolnością serca ze zredukowaną frakcją wyrzucania lewej komory. Bardzo prosimy o zapoznanie się z kartą wypisową, w której opisano podjęte leczenie, współistniejące schorzenia, rokowanie, aktualną klasyfikację objawów oraz zalecone leczenie, które pacjent otrzymuje na tym etapie swojej choroby. Pozwalamy sobie jednocześnie przypomnieć, że pacjent z niewydolnością serca ze zredukowaną frakcją wyrzucania lewej komory (LVEF, left ventricular ejection fraction) - wedle najnowszych obowiązujących wytycznych Europejskiego Towarzystwa Kardiologicznego dotyczących leczenia tej grupy osób - powinien, jeżeli nie ma przeciwwskazań, poza ogólnymi zaleceniami (leczenie moczopędne w celu zmniejszenia przewodnienia, indywidualne rozważenie profilaktycznego wszczepienia kardiowertera-defibrylatora u pacjentów z LVEF $\leq 35 \%$ w celu prewencji nagłego zgonu sercowego), otrzymać:

- w pierwszym kroku leczenia: inhibitor konwertazy angiotensyny (inhibitor ACE) oraz beta-adrenolityk i mieć dawki tych leków zwiększane do maksymalnie tolerowanych;

- w drugim kroku leczenia: antagonistę aldosteronu w maksymalnej tolerowanej dawce - u chorych z utrzymującymi się objawami i LVEF $\leq 35 \%$;

- w trzeci kroku leczenia: u chorych z utrzymującymi się objawami i LVEF $\leq 35 \%$ należy rozważyć jedną z trzech opcji leczenia: skierowanie chorego do wszczepienia układu resynchronizującego (CRT), jeżeli ma do tego dodatkowe wskazania, LUB zastosowanie nowej grupy leków zamiast dotychczas przyjmowanego inhibitora ACE (tzw. leki z grupy ARNI), LUB zastosowanie iwabradyny.

Dobierając odpowiednią interwencję w trzecim kroku i zastanawiając się nad częstością ich stosowania i łączenia, warto sugerować:

- pierwszeństwo stosowania CRT u pacjentów z blokiem lewej odnogi pęczka Hisa i szerokością zespołów QRS > 150 ms (ta grupa korzysta najbardziej z tej formy terapii);

- pierwszeństwo stosowania iwabradyny u pacjentów z rytmem zatokowym i częstością akcji serca $\geq 75 /$ min pomimo stosowania beta-adrenolityków lub przy ich nietolerancji; 
- pierwszeństwo wdrażania ARNI zamiast dotychczasowych inhibitorów ACE, jeżeli pacjent ma takie możliwości finansowe (leczenie nierefundowane aktualnie w Polsce), ma nadal objawy, LVEF $\leq 35 \%$, podwyższone wartości peptydów natriuretycznych (BNP $\geq 150$ pg/ml lub NT-pro-BNP $\geq 600$ pg/ml).

Warto jednak pamiętać, że wszystkie trzy sposoby postępowania w trzecim kroku terapeutycznym można ze sobą dowolnie łączyć.

IWABRADYNA jest najczęściej wybieraną składową trzeciego kroku terapeutycznego w terapii niewydolności serca w Polsce. Jest coraz częściej wypisywana łącznie z beta-adrenolitykiem przy opuszczaniu przez chorego oddziału szpitalnego, po optymalizacji leczenia niewydolności serca. Jeżeli jednak Państwa pacjent nie otrzymał jeszcze iwabradyny, aby zastosować ją w refundowanej w Polsce terapii, wystarczy Państwa adnotacja w dokumentacji chorego informująca, że:

- pacjent ma niewydolność serca, klasyfikowaną w skali NYHA II-IV, i obniżoną frakcję wyrzucania lewej komory (niewymagana jest osobna konsultacja kardiologa, można podeprzeć się wcześniejszą dokumentacją i wykonanym w przeszłości badaniem echokardiograficznym, nie ma obowiązku jego powtarzania);

- pacjent jest leczony zgodnie z wytycznymi, w tym optymalną tolerowaną dawką beta-adrenolityku, lub ma przeciwwskazania do terapii beta-adrenolitykiem;

- w wykonanym EKG stwierdzono rytm zatokowy i częstość akcji serca $\geq 75 /$ min (niewymagane jest przechowywanie zapisu EKG, jedynie zamieszczenie dokładnego opisu w dokumentacji); uwaga: kryterium częstości akcji serca $\geq 75 /$ min jest koniecznym warunkiem refundacji, chociaż korzyści kliniczne i wytyczne wskazują już na częstość akcji $\geq 70 /$ min jako wskazania do dołączenia tego leku. Przedział częstości akcji serca 70-74/min w momencie włączenia jest nadal nierefundowany.

Po stwierdzeniu tych faktów i odnotowaniu ich na tej samej wizycie natychmiastowe włączenie iwabradyny jest zgodne z zapisem refundacji. Osiągnięcie przez pacjenta celu leczenia redukcji częstości akcji serca, na przykład do $<60 / \mathrm{min}$, nie pozbawia go refundacji leku, a dalsza dokumentacja zasadności podawania iwabradyny nie jest konieczna.

Bardzo prosimy o nadzór nad realizacją określonych wyżej kroków terapeutycznych, nieodwlekanie decyzji o ich zastosowaniu i wdrażaniu jak najwcześniej nowoczesnej terapii.

Zwracamy się również z prośbą o nieodstawianie bez uzasadnionych przyczyn leków przedłużających życie pacjentom z niewydolnością serca: inhibitorów ACE, leków beta-adrenolitycznych, antagonistów aldosteronu, iwabradyny.

W razie jakichkolwiek wątpliwości zachęcamy do kontaktu z ośrodkiem specjalizującym się w terapii niewydolności serca. 